\title{
The resurgence of pertussis
}

\section{J. Brad Wiggers MD, Jerome A. Leis MD MSc, Wayne L. Gold MD}

\section{Pertussis is a highly communicable respiratory tract infection}

Pertussis (whooping cough) is caused by the bacterium Bordetella pertussis. In children, pertussis classically presents with paroxysms of coughing followed by a post-tussive inspiratory whooping sound. ${ }^{1}$ In older individuals, its sole manifestation may be protracted cough; therefore, pertussis should be on the differential diagnosis for any adolescent or adult with protracted cough, regardless of their immunization status. ${ }^{2}$ Infants are at greatest risk of complications, including otitis media, pneumonia, encephalopathy, seizures and death. ${ }^{1}$

The diagnostic test of choice is polymerase chain reaction testing of a nasopharyngeal aspirate

The polymerase chain reaction assay is available through most provincial laboratories. ${ }^{3}$ Serologic testing has no role in the acute stages of illness, but it may be helpful for diagnosis late in the infection in people who have not been previously vaccinated. The lack of widely available serologic tests with established cutoff points limits their usefulness. ${ }^{1}$ Consultation with local laboratories regarding availability of testing is recommended.

\section{References}

1. Pertussis (whooping cough). In: Pickering LK, Baker CJ, Kimberlin DW, et al., editors. Red Book: 2009 report of the Committee on Infectious Diseases. 29th ed. Elk Grove Village (IL): American Academy of Pediatrics; 2009:553-65.

2. Pertussis vaccine. In: National Advisory Committee on Immunization. Canadian immunization guide part 4 - active vaccines. Ottawa: Public Health Agency of Canada; 2014. Available: www.phac -aspc.gc.ca/publicat/cig-gci/p04-pert-coqu-eng.php (modified 2014 May 14; accessed 2014 Aug. 22).

3. Public Health Agency of Canada. Proceedings of the National Microbiology Laboratory Pertussis Workshop. Can Dis Wkly Rep 2006;32(S4):1-22.

\section{Macrolides are the mainstay of ther- apy and prophylaxis}

Antibiotic therapy may reduce symptom severity only if started within a week after symptom onset. ${ }^{1,4}$ However, treatment up to eight weeks after symptom onset should be considered in patients who are likely to be in contact with people at high risk, such as infants and women in the third trimester of pregnancy. ${ }^{4}$ Chemoprophylaxis is recommended in close contacts if exposure occurs within 21 days after symptom onset in the index case. ${ }^{1}$ For exposed infants and for households with people at high risk, prophylaxis up to eight weeks after exposure should be considered., ${ }^{1,4}$

4. Hewlett EL, Edwards KM. Clinical practice. Pertussis - not just for kids. N Engl J Med 2005 352:1215-22.

5. Deeks SL, Lim GH, Walton R, et al. Prolonged pertussis outbreak in Ontario originating in an underimmunized religious community. Can Dis Wkly Rep 2014;40(3):42-9.

6. Publicly-funded immunization programs in the provinces and territories of Canada - routine and high risk (HR) schedule for adults (as of September 2014). Ottawa: Public Health Agency of Canada. Available: www.phac-aspc.gc.ca/im /ptimprog-progimpt/table-3-eng.php (accessed 2014 Aug. 26).
The resurgence of pertussis has been linked to waning immunity

Immunity wanes after the primary childhood immunization series. ${ }^{1}$ In recent years, increased rates of infection have been seen in adolescents and adults. ${ }^{3}$ Infected people, including those with only mild disease, can act as a reservoir for spread to nonimmunized infants and incompletely immunized children, adolescents and adults. ${ }^{4}$ The secondary attack rate in susceptible household contacts is $80 \%{ }^{2}$

Pertussis vaccines are indicated for children, adolescents and adults

Low vaccination coverage has been linked to recent outbreaks. ${ }^{5}$ The Canadian National Advisory Committee on Immunization recommends five childhood doses and a booster dose at 14 16 years. $^{2}$ It recommends that all adults 18 years or older should receive a single dose of tetanus-diphtheria-acellular pertussis vaccine. Parents, grandparents and childcare providers who have not received an adult dose should be prioritized for vaccination. ${ }^{2}$ Because variations exist, physicians should be familiar with their own provincial funding mechanisms for immunizations. ${ }^{6}$

Competing interests: None declared.

This article has been peer reviewed.

Affiliations: Department of Medicine (Wiggers), University of Toronto; Division of Infectious Diseases (Leis, Gold), Department of Medicine, University of Toronto; Centre for Quality Improvement and Patient Safety (Leis), University of Toronto, Toronto, Ont.

Correspondence to: Wayne L. Gold, wayne.gold @uhn.ca

CMAJ 2015. DOI:10.1503/cmaj.140896 